\title{
Bakır ve Kurşunun Oreochromis niloticus'da Hepatosomatik İndeks, Gonadosomatik İndeks ve Kondüsyon Faktörü Üzerine Etkileri
}

\author{
Nuray ÇIFTÇI*, Cengiz KORKMAZ, Özcan AY, Fahri KARAYAKAR, Bedii CİCIK
}

Mersin Üniversitesi, Su Ürünleri Fakültesi, Yenişehir Kampüsü, Mersin

Geliş $\quad: 21.04 .2016$

Kabul : 18.08 .2016

*Sorumlu yazar: nciftci@ mersin.edu.tr

Araştırma Makalesi / Research Article

E-Dergi ISSN: $1308-7517$

\section{Özet}

Araștırmada bakır $(\mathrm{Cu})$ ve kurșun $(\mathrm{Pb})$ 'un 96 saatlik $\mathrm{LC}_{50}$ değerinin \%10'una karșıllk gelen derișimlerinin (sırasıyla 4,0 ve 0,2 ppm) 7, 15 ve 30 gün sürelerde etkisine birakılan Oreochromis niloticus'un Hepatosomatik İndeks (HSI), Gonadosomatik Indeks (GSI) ve Kondüsyon Faktörü (CF) üzerine etkisinin belirlenmesi amaçlanmıştır. Belirtilen parametrelerin hesaplanmasında standart matematiksel formüller kullanılmış, verilerin istatistiksel analizinde, Student Newman Keul's testi ile varyans analizi uygulanmıştır. Denemede $\mathrm{Cu}$ etkisine bırakılan balıklarda HSI'de kontrole göre artış, GSI ve CF'nde deneme süresi sonunda azalma saptanırken, $\mathrm{Pb}$ etkisine bırakılan balıklarda HSI'de kontrole göre azalma $(\mathrm{P}<0,05)$, GSI ve CF'nde ise istatistiksel olarak önemli bir fark saptanmamıştır $(\mathrm{P}>0,05)$.

Anahtar kelimeler: Bakır, kurşun, Oreochromis niloticus, somatik indeks, kondüsyon faktörü

The Effects of Copper and Lead on Hepatosomatic Index, Gonadosomatic Index and Condition Factor of Oreochromis niloticus

\begin{abstract}
Oreochromis niloticus was exposed to $10 \%$ of its $96 \mathrm{~h} \mathrm{LC50} \mathrm{(4.0} \mathrm{ppm} \mathrm{Cu} \mathrm{and} 0.2 \mathrm{ppm} \mathrm{Pb}$ ) over 7, 15 and 30 days and their effects on hepatosomatic index (HSI), gonadosomatic index (GSI) and condition factor (CF) were determined. Standard mathematical formulas were used to express the parameters and analaysis of variation and Student Keul's test were applied to analyse data.. An increase in HSI and decreases in GSI and $\mathrm{CF}$ were observed in fish exposed to copper compared to the control. However, a decrease in HIS was observed when fish were exposed to $\mathrm{Pb}(\mathrm{P}>0.05)$ compared to the control and also no significant differences in GSI and CF $(\mathrm{P}<0.05)$ were determined.
\end{abstract}

Keywords: Copper, lead, Oreochromis niloticus, somatic indices, condition factor.

\section{GİRIŞ}

Nüfus artışı ve yaşam kalitesini iyileştirmeyi hedefleyen endüstriyel gelişimler, ağır metallerin hammadde olarak kullanımını arttırırken işlenme sırasında meydana gelen atıkların, arıtılmaksızın çevreye verilmesi, ağır metallerin doğal ortamlardaki özellikle başlıca alıcı ortam olan sucul ekosistemlerdeki derişimlerinin artmasına neden olmuştur (Bettini vd., 2006). Ağır metal derişimindeki artış, suyun fiziksel ve kimyasal özelliklerinde değişime neden olduğu gibi, sucul organizmaların doku ve organlarında birikime, metabolik ve fizyolojik olaylarda değişikliklere sonuçta mortaliteye neden olduğu görülür (Levesque vd., 2002).

Ağır metallerin bir kısmı, hayvansal organizmalar tarafından yaşamsal olaylar için düşük derişimlerde gereksinim duyulurken, bir kısmı çok düşük derişimlerde de toksik etkilidir. Bunlardan bakır, yaklaşık 30 kadar enzim ve glikoproteinin yapısal bileşimine 
giren bir iz element olup (Goyer vd., 1986), omurgalı hayvanlarda demirin sindirim sisteminden absorbsiyonunda, hemoglobin sentezinde, sinir sistemindeki miyelin kılıfın sürekliliğinde, beyin ve kemik doku oluşumunda işlev görür (Kruger, 2002). Bakır, yerkabuğunda doğal olarak bulunurken, elektrik endüstrisi başta olmak üzere, alaşım, kimyasal katalizör, boya ve ahşap koruyucu, yapımında yaygın bir şekilde kullanılmaktadır (Eisler, 2000). Doğa ve laboratuvar koşullarında çeşitli balık türleri ile yürütülen araştırmalarda bakırın solungaç, karaciğer ve böbrek gibi metabolik bakımdan aktif organlarda yüksek derişimlerde biriktiği (Cicik, 2003), osmoregülasyon, lokomasyon davranışını etkilediği (Eisler, 2000), doku ve organlarda histopatolojik (Hilmy vd., 1987), serum biyokimyasal parametrelerinde değişimlere neden olduğu (Hollis vd., 2001), büyümeyi engellediği, oksijen tüketimini ve amonyak salınımını arttırdığı, yumurtlama sıklığını azalttığı bildirilmiştir (Eisler, 2000).

Kurşun düşük derişimlerde de toksik etkili bir ağır metaldir. Günümüzde yap1 metalleri, levha, tel ve kablo imalatında, patlayıcı fitili üretiminde ve kauçuk sanayinde yaygın bir şekilde kullanılmaktadır (Dündar ve Aslan, 2005). Balıklarda kurşun etkisinin, yumurta sarısının emilim oranını düşürdüğü, yumurtadan çıkma oranında azalmaya neden olduğu dolayısıyla üreme başarısını olumsuz yönde etkilediği, iskelet sisteminde deformasyonlara, dolaşım sisteminde bozukluklara neden olduğu bildirilmiştir (Kruger,2002).

Kondüsyon faktörü, hepatosomatik indeks ve gonadosomatik indeks canlının büyüme gelişme ve üreme durumunu yansıtan önemli parametrelerdir. Stokların sürdürülebilirliği ve popülasyon sağlığının ortaya konmasında yaygın bir şekilde kullanılmaktadırlar (Vives vd., 2004; Martin-Diaz vd., 2005).

Akuatik ekosistemlerdeki ağır metal kirliliğinin incelenmesi, gerek su kaynaklarının korunması gerekse su ürünlerinin sürdürülebilirliği açısından oldukça önemli olduğu için bu araştırmada biri iz diğeri toksik etkili iki farklı ağır metalin 96 saatlik $\mathrm{LC}_{50}$ değerinin $\% 10$ 'una karşılık gelen derişimlerinin 7,15 ve 30 gün sürelerle etkisine birakılan $O$. niloticus'da kondüsyon faktörü, hepatosomatik indeks ve gonadosomatik indeksde meydana gelen değişimlerin belirlenmesi amaçlanmıştır.

\section{MATERYAL ve YÖNTEM}

Araştırmada materyal olarak, 18,58 $\pm 0,91 \mathrm{~cm}$ boy ve 110,27 $\pm 13,29$ g ağırlığa sahip O. niloticus türü balıklar kullanılmıştır. Balıklar, Mersin Üniversitesi Su Ürünleri Fakültesi Uygulama Birimlerinde yer alan yetiştiricilik havuzlarından sağlanmış ve deneyler kontrollü ortam koşullarına sahip $\left(24 \pm 1^{\circ} \mathrm{C}\right.$ durağan sıcaklık; 12 saat aydınlık, 12 saat karanlık fotoperiyodu) Temel Bilimler Araştırma Laboratuvarında yürütülmüştür. Laboratuara getirilen balıklar, her biri $40 \times 100 \times 40 \mathrm{~cm}$ boyutlarında 3 adet cam akvaryum içerisinde iki hafta süreyle bekletilerek ortam koşullarına uyumları sağlanmıştır.

Deneylerde bakır ve kurşunun $O$. niloticus için 96 saatlik $\mathrm{LC}_{50}$ değerinin \%10'una karşılık gelen sırasıyla 4,0 ve 2,0 ppm'lik ortam derişimleri 7,15 ve 30 gün süre ile uygulanmıştır. Deneyler 2 seri halinde, 3 tekrarlı olarak yürütülmüştür ve her tekrarda bir adet balık kullanılmıştır. Bu amaçla 3 adet cam akvaryum kullanılmış, akvaryumlardan ilk ikisine sırasıyla bakır (4.0 ppm) ve kurşunun (0.2 ppm) 120'şer L çözeltileri konurken, üçüncü akvaryuma aynı hacimde metal içermeyen dinlenmiş çeşme suyu konmuş ve kontrol grubu olarak incelenmiştir. Belirlenen süreler dikkate alınarak akvaryumların her birine 18 adet balık konmuş ve deneme süresince toplam 54 adet balık kullanılmıştır. 
Deney ve kontrol akvaryumlarında suyun sicaklık $\left(24 \pm 1{ }^{\circ} \mathrm{C}\right), \mathrm{pH}(8,62 \pm 0,16)$, çözünmüş oksijen $\left(5,29 \pm 0,7 \mathrm{mgL}^{-1}\right)$, toplam sertlik $\left(227 \pm 0,48 \mathrm{mgL}^{-1} \mathrm{CaCO} 3\right)$ ve alkalinite $\left(332 \pm 0,50 \mathrm{mgL}^{-1} \mathrm{CaCO}_{3}\right)$ değerleri belirlenmiştir.

Metal çözeltilerinin hazırlanmasında bakır ve kurşunun sırasıyla suda çözünebilen $\mathrm{CuSO}_{4} .5 \mathrm{H}_{2} \mathrm{O}$ ve $\mathrm{Pb}\left(\mathrm{NO}_{3}\right)_{2}$ tuzları kullanılmıştır. Metal tuzlarının presipitasyonunu önlemek amacıyla stok solüsyonlar hazırlanırken trisodyumsitrat eklenmiştir.

Araştırma süresince balıklar, günde bir kez toplam biyomasın \% 2'si kadar hazır balık yemi (Pınar, Çipura Yemi, Pelet No.2) ile beslenmiştir. Akvaryumlarda havalandırma merkezi havalandırma sistemi ile sağlanmıştır.

Deney ve kontrol akvaryumlarında evaporasyon, presipitasyon ve adsorbsiyon gibi nedenlerle deney çözeltilerinin derişiminde zamana bağlı değişimler olabileceğinden deney çözeltileri her iki günde bir stok çözeltiden uygun seyreltmeler yapılarak değiştirilmiş ve ortam yenilenmiştir.

Belirlenen süreler sonunda deney akvaryumlarından çıkarılan balıklar, Etilen Glikol Mono Fenil Eter (= Fenoksietanol, $\mathrm{C}_{8} \mathrm{H}_{10} \mathrm{O}_{2}$; Merck) anestezik maddesi ile bayıltılııştır. Vücut yüzeyindeki metal rezidüleri çeşme suyu ile yıkanıp uzaklaştırıldıktan sonra balıklar kurutma kağıdı ile kurulanıp, ölçüm ve örneklemelere hazır hale getirilmiştir.

Somatik indeks analizleri için balıkların her birinin toplam boy ve ağırlıkları belirlendikten sonra disekte edilerek karaciğer ve gonadları çıkartılmış ve yaş ağırlıkları belirlenmiştir.

Toplam boy, ağırlık ve organ yaş ağırlık verilerine aşağıda sırasıyla verilen matematiksel formülasyonlar uygulanarak (Biney vd.,1994) hepatosomatik indeks, gonadosomatik indeks ve kondüsyon faktörü hesaplanmıştır.

$$
\begin{aligned}
& H S I(\%)=\frac{K \cdot Y \cdot A \cdot(g)}{T \cdot V \cdot A \cdot(g)} \times 100 \\
& G S I(\%)=\frac{G \cdot Y \cdot A \cdot(g)}{T \cdot V \cdot A \cdot(g)} \times 100 \\
& C F(\%)=\frac{T \cdot V \cdot A \cdot(\mathrm{g})}{T L^{3}(\mathrm{~cm})} \times 100
\end{aligned}
$$

$\begin{array}{ll}\text { HSI } & \text { : Hepatosomatik İndeks } \\ \text { GSI } & \text { : Gonadosomatik İndeks } \\ \text { CF } & : \text { Kondüsyon Faktörü } \\ \text { KYA } & \text { : Karaciğer Yaş Ağırlık } \\ \text { GYA } & : \text { Gonad Yaş Ağırlık } \\ \text { TVA } & : \text { Toplam Vücut Ağırlığı } \\ \text { TL } & \text { : Toplam Boy }\end{array}$

Deney verilerinin istatistik analizinde SPSS paket programı kullanılmış ve Student Newman Keul's (SNK) testi ile varyans analizi uygulanmıştır. İncelenen parametrelere ait veriler yüzde (\%) olduğundan, istatistik analizden önce verilere Arksin transformasyonu uygulanmıştır. 


\section{BULGULAR}

Araştırmada bakır ve kurşunun incelenen derişimleri deneme süresince balıklarda mortaliteye neden olmamıştır.

Denemede $\mathrm{Cu}$ etkisine bırakılan balıklarda HSI'de kontrole göre artış, GSI ve CF'nde deneme süresi sonunda azalma saptanırken, $\mathrm{Pb}$ etkisine birakılan balıklarda HSI'de kontrole göre azalma $(\mathrm{P}<0,05)$, GSI ve $\mathrm{CF}$ 'nde ise istatistiksel olarak önemli bir fark saptanmamıştır $(\mathrm{P}>0,05)$ (Tablo 1).

Tablo 1. Bakır ve kurşunun O. niloticus'da HSI, GSI ve CF Üzerine Etkileri

\begin{tabular}{|c|c|c|c|c|c|}
\hline & \multirow{3}{*}{$\begin{array}{c}\text { Metal } \\
\text { (derişim) }\end{array}$} & \multicolumn{4}{|c|}{ Süre (Gün) } \\
\hline & & 0 (Kontrol) & 7 & 15 & 30 \\
\hline & & $\bar{X} \pm S \bar{x} *$ & $\bar{X} \pm S \bar{x} *$ & $\bar{X} \pm S \bar{x} *$ & $\bar{X} \pm S \bar{x} *$ \\
\hline \multirow{2}{*}{$\begin{array}{l}\text { HSI } \\
(\%)\end{array}$} & $\begin{array}{c}\mathrm{Cu} \\
(4,0 \mathrm{ppm})\end{array}$ & $1,53 \pm 0,025^{\mathrm{a}}$ & $1,53 \pm 0,07^{\mathrm{a}}$ & $2,51 \pm 0,23^{b}$ & $1,82 \pm 0,006^{\mathrm{a}}$ \\
\hline & $\begin{array}{c}\mathrm{Pb} \\
(0,2 \mathrm{ppm})\end{array}$ & $1,74 \pm 0,014^{\mathrm{a}}$ & $1,77 \pm 0,19^{\mathrm{a}}$ & $1,14 \pm 0,003^{\mathrm{b}}$ & $1,14 \pm 0,070^{\mathrm{b}}$ \\
\hline \multirow{2}{*}{$\begin{array}{l}\text { GSI } \\
(\%)\end{array}$} & $\begin{array}{c}\mathrm{Cu} \\
(4,0 \mathrm{ppm})\end{array}$ & $0,53 \pm 0,045^{\mathrm{a}}$ & $0,61 \pm 0,028^{\mathrm{ab}}$ & $0,68 \pm 0,036^{\mathrm{b}}$ & $0,41 \pm 0,010^{\mathrm{c}}$ \\
\hline & $\begin{array}{c}\text { Pb } \\
(0,2 \text { ppm })\end{array}$ & $0,56 \pm 0,012^{a}$ & $0,67 \pm 0,30^{\mathrm{a}}$ & $0,57 \pm 0,26^{\mathrm{a}}$ & $0,58 \pm 0,052^{\mathrm{a}}$ \\
\hline \multirow{2}{*}{$\begin{array}{l}\mathbf{C F} \\
(\%)\end{array}$} & $\begin{array}{c}\text { Cu } \\
(4,0 \mathrm{ppm})\end{array}$ & $1,85 \pm 0,038^{\mathrm{a}}$ & $1,69 \pm 0,017^{\mathrm{b}}$ & $1,45 \pm 0,080^{\mathrm{c}}$ & $1,50 \pm 0,029^{c}$ \\
\hline & $\begin{array}{c}\text { Pb } \\
(0,2 \text { ppm })\end{array}$ & $1,86 \pm 0,008^{\mathrm{a}}$ & $1,86 \pm 0,067^{\mathrm{a}}$ & $1,76 \pm 0,060^{\mathrm{a}}$ & $1,67 \pm 0,049^{\mathrm{a}}$ \\
\hline
\end{tabular}

*SNK; a, b ve c harfleri sürelerarası farkı belirlemek amacı ile kullanılmıştır. Aynı satırda farklı harflerle gösterilen veriler arasında istatistik fark vardır $(\mathrm{P}<0,05)$.

$\overline{\mathrm{X}} \pm \mathrm{S} \overline{\mathrm{x}}:$ Aritmetik Ortalama \pm Standart Hata

\section{TARTIŞMA ve SONUÇ}

O. niloticus ile yürütülen bu çalışmada, bakır ve kurşunun sırasılyla 4,0 ve 0,2 ppm'lik derişimlerinin 7, 15, ve 30 günlük sürelerdeki etkileri balıklarda mortaliteye neden olmamıştır. Channa punctatus'da Cr'un (Sastry ve Sunita, 1984), Anguilla anguilla' da Cu'ın (Karayakar vd., 2010), sublethal derişimlerinin kronik etkisinde balıklarda mortalite saptanmadığı bildirilmiştir. Mortalitenin gözlenmemesi seçilen derişimlerin belirlenen süreler içerisinde anılan tür için letal etkili olmamasından kaynaklanabileceği gibi atılım ve detoksifikasyon mekanizmalarının stimülasyonundan kaynaklanabilir.

Kirliliğin de yer aldığı stres faktörleri; sucul organizmalarda metabolik, fizyolojik ve biyokimyasal olaylarda değişikliklere dolayısıyla büyüme, gelişme ve üremenin olumsuz yönde etkilenmesine neden olur (Heath, 1995).

Hepatosomatik indeks, hayvansal organizmalarda metabolik aktivitenin genel durumunu yansıtan önemli indikatör parametrelerden biridir. O. niloticus'da bakır (ElSerafy vd., 2013), kurşun (Abbas, 1994), Clarias lazera' da kurşun ve kadmiyum (Habib ve Samah, 2013) etkisinin HSI'i kontrole göre düşürdügü belirlenmiştir. Metal etkisinde HSI'deki bu düşmenin karaciğerdeki mevcut enerji rezervlerinin metal toksisitesi ile mücadelede yoğun bir şekilde kullanılmasından kaynaklanabileceği bildirilmiştir (Bekmezci, 2010). Bakır içerikli besinle beslenen Cyprinus carpio'da HSI'in arttı̆̆ belirtilmiştir (Ajani ve Akpoilih, 2012). O. niloticus ile yürütülen bu araştırmada da $\mathrm{Cu}$ 
etkisi HSI'i arttırırken, Pb etkisinin HSI'i düşürdüğü belirlenmiştir. Metal etkisinde HSI'deki artışın, detoksifikasyonda işlev gören metal bağlayıcı proteinlerle karaciğer orijinli proteinlerin sentezindeki artıştan kaynaklanabileceği gibi, HSI'deki düşmenin hepatositlerdeki enerji rezervlerinin tüketilmesinden kaynaklanabileceği olasıdır.

Gonadosomatik indeks, gerek bir türün neslinin sürekliliği için popülasyonun durumunu yansıtması, gerekse kirletici etkisine bağlı olarak organizmada gelişen değişimleri yansıtması bakımından oldukça önemli parametrelerden biridir. Çeşitli balık türleri ile yapılan araştırmalarda ağır metal etkisinin (Sindhe ve Kulkarni 2004; El-Serafy vd., 2013) GSI'i düşürdüğü belirlenmiştir. Mullus barbatus'da Pb etkisinde GSI'deki düşmenin, DNA'nın yapısal bütünlügüündeki bozulma ve karaciğer EROD (ethoxyresorufin-O deethylase) aktivitesindeki artışa bağlı olabileceği bildirilmiştir (Martinez-Gomez vd., 2012). Yine Leuciscus cephalus ile yürütülen bir diğer araştırmada da ağır metal etkisine bağlı gonad büyüklügüundeki değişimlerin plazma 11ketotestosteron, EROD ve vitellojen miktarındaki azalma ile ilişkili olabileceği belirtilmiştir (Randak vd., 2008). O. niloticus ile yapılan bu çalışmada da, Cu etkisinin başlangıçta GSI'i arttırırken, etkide kalma süresi arttıkça düşürdüğü belirlenmiş ve bu değişimlerin istatistiksel bakımdan anlamlı olduğu tespit edilmiştir $(\mathrm{p}<0,05)$. Cu etkisinin başlangıcında GSI'de kontrole oranla gözlenen artışın, Cu'ın üreme ile ilgili enzim ve hormonları stimüle etmesinden kaynaklanabileceği düşünülmektedir. Etkide kalma süresinin uzaması sonucu GSI'deki azalmanın ise bakırın da belirli bir derişim aralığı üzerinde gonadlarda toksik etkili olmasından kaynaklanabilir. Çalışmada, Pb'nun GSI üzerine etkisinin kontrol grubuna göre istatistiksel bakımdan anlamlı olmadığı tespit edilmiştir $(\mathrm{P}>0,05)$. Bu durum $O$. niloticus'da kurşunun belirlenen derişiminin incelenen sürelerde anılan parametrede değişikliğe neden olacak kadar yüksek ve etkili olmamasından kaynaklanabilir.

Kondüsyon faktörü, balıklarda genel sağlık durumunu yansitan diğer bir parametre olup beslenme durumuna, yaşa, eşeye ve üreme dönemine bağlı olarak değişim gösterir (Y1lmaz vd., 2007). Gasterosteus aculeatus (Sanchez vd., 2008) ve Gobio gobio (Bervoets ve Blust, 2003)'da ağır metal etkisi CF'ünü düşürürken, Astyanax fasciatus (Alberto vd., 2005)'da arttırdığ 1, Clarias gariepinus (Hamoud Balawi-Alkahemal vd., 2011)'da ise her hangi bir değişime neden olmadığı bildirilmiştir. Metal etkisinde CF'ündeki bu değişimlerin; iştah kaybı, enerji gereksinimlerindeki artışa bağlı olarak enerji rezervlerindeki düşmeden kaynaklanabileceği belirtilmiştir.

O. niloticus ile yürütülen bu araştırmada bakırın etkide kalma süresine bağlı olarak CF'ünü kontrol grubuna göre düşürdüğü ve değişimlerin istatistiksel bakımdan anlamlı olduğu belirlenmiştir $(\mathrm{P}<0,05)$. Cu etkisinde $\mathrm{CF}$ 'ünde belirlenen düşmenin metal etkisine bağlı metabolik aktivitedeki artış ve stres koşullarının gereği enerji rezervlerinin tükenmesinden kaynaklanabileceği olasıdır. $\mathrm{Pb}$ etkisinde anılan parametredeki değişimlerin kontrol grubuna göre istatistiksel bakımdan anlamlı olmadığı tespit edilmiştir $(\mathrm{P}>0,05)$.

Sonuç olarak $O$. niloticus'da metabolik aktivite, genel sağlık ve üreme durumunun bakır ve kurşun gibi ağır metallerden etkilendiği görülür. 


\section{KAYNAKLAR}

Abbas, H. H. (1994). Effect of lead on some physiological aspects of nile tilapia; Oreochromis niloticus, M. Sc. Thesis, Cairo University, Cairo.

Ajani, E. K., \& Akpoilih, B. U. (2012). Growth response and ionic regulation in common carp (Cyprinus carpio L.) after chronic dietary copper exposure and recovery. International Journal of Fisheries and Aquaculture, 4(2), 13-21.

Alberto, A., Camargo, A. F. M., Verani, J. R., Costa, O. F. T., \& Fernandes, M. N. (2005). Health variables and gill morphology in the trophical fish Astyanax fasciatus from a sewage contaminated river. Ecotoxicology and Environmental Safety, 61, 247-255.

Bekmezci, H. D. (2010). Aşağı Seyhan Ovası drenaj sistemlerindeki kirlilik etmenlerinin Clarias gariepinus'da toksik etkileri. Çukurova Üniversitesi, Fen Bilimleri Enstitüsü, Biyoloji ABD, Doktora Tezi, 145.

Bervoets, L., \& Blust, R. (2003). Metal concentrations in water, sediment and gudgeon (Gobio gobio) from a pollution gradient: relationship with fish condition factor. Environmental Pollution, (126), 9-19.

Bettini, S., Ciani, F., \& Franceshini, V. (2006). Recovery of the olfactory receptor neurons in the African tilapia marine following exposure to low copper level. Aquatic Toxicology, (76), 321-328.

Biney, C., Amazu, A. T., Calamari, D., Kaba, N., Mbome, I. L., Naeve, H., Ochumba, P. B. O., Osibonjo, O., Radegonde, V., \& Saad, M. A. H. (1994). Review of heavy metals in the African aquatic environment. Ecotoxicology and Environmental Safety, (31), 134-159.

Cicik, B. (2003). Bakır-Çinko etkileşiminin sazan (Cyprinus carpio)'nın karaciğer, solungaç ve kas dokularındaki metal birikimi üzerine etkileri, Ekoloji Çevre Dergisi, 12(48), 32-36.

Dündar, Y., \& Aslan, R. 2005. Yaşamı kuşatan ağır metal kurşunun etkileri. Kocatepe Tıp Dergisi, 6,1-5.

Eisler, R. (2000). Handbook of Chemical Risk Assessment Health Hazards to Humans, Plants, and Animals. United States of America, 1, 844 pp.

El-Serafy, S. S., Zowail, M. E., Abdel-Hameid, N. A. H., Awwad, M. H., \& Omar, E. H. (2013). Effect of diet borne $\mathrm{Cu}$ and $\mathrm{Cd}$ on body indices of nile tilapia (Oreochromis niloticus) with emphasis on protein pattern. Turkish Journal of Fisheries and Aquatic Sciences, 13(4), 593602.

Goyer, R. A., Klaassen, C. D, Amdur, M. O., \& Doull, J. (Eds). (1986). Casarettand Doull's Toxicology The Basic Science of Poisons, Macmillian Publ. Co., New York, 582.

Habib, S. A., \& Samah, S. (2013). Effect of heavy metals pollution on protein biosynthesis in catfish, Journal of Water Resource and Protection, (5), 555-562.

Heath, A. G. (1995). Water pollution and fish physiology. CRC Press, Boca Raton, FL, 339.

Hilmy, A. M., El Domiaty, N. A., Daabees, A. Y., Abdel Latife, \& H. A., (1987). Some physiological and biochemical indices of zinc toxicity in two fresh water fishes, Clarias lazera and Tilapia zilli. Comp. Biochem. Physiol. C, 87(2),297-301.

Hamoud Fares Alkahemal-Balawi, Z. A., Al-Akel, A. S., Al-Misned, F., El-Amin, M. S., \& AlGhanim, K. A. (2011). Toxicity bioassay of lead acetatean deffects of its sublethal exposure on growth, haematological parameters and reproduction in Clarias gariepinus, African Journal of Biotechnology, 10(53),11039-11047.

Hollis, L., Hogstrand, C., \& Wood, C. M. (2001). Tissue specific cadmium accumulation metallohionein induction and tissue zinc and copper ligands during chronic sublethal cadmium exposure in juvenile rainbow trout. Arch. Environ. Contam. Toxicol., 41(4), 468474.

Karayakar, F., Cicik, B., Çiftçi, N., Karaytuğ, S., Erdem, C., Ay, Ö., (2010). Accumulation of copper in liver, gill and muscle tissues of Anguilla anguilla (Linnaeus, 1758). J. of Animal and Veterinary Advances, 9(17), 2271-2274. 
Kruger, T. (2002). Effects of zinc, copper and cadmium on Oreochromis mossambicus freeembryos and randomly selected mosquito larvae as biological indicators during acute toxicity testing, Rand Afrikaans University, Faculty of Science, Johannesburg S.A, 156.

Levesque, H. M., Moon, T. W., Campbell, P. G. C., \& Hontela, A. (2002).Seasonal variation in carbonhydrate and lipid metabolism of yellow perch (Perca flavescens) chronically exposed to metals in the field. Aquatic Toxicology, 60(3-4),257-267.

Martin-Diaz, M., Tuberty, S., McKenney, C., Sales, D., \& DelVals, T. (2005). Effects of cadmium and zinc on Procambarus clarkii: simulation of the aznal collarmining spill, Ciencias Marinas, 62(1),113-124.

Martínez-Gómez, C.,Fernández, B., Benedicto, J., Valdés, J., Campillo, J. A.,León, V. M., \& Vethaak, A. D. (2012). Health status of red mullets from polluted areas of the Spanish Mediterranean Coast, with special reference to Portmán (SE Spain). Marine Environmental Research, 77,50-59.

Randak, T., Zlabek, V., Pulkrabova, J., Kolarova, J., Kroupova, H., Siroka, Z., Velisek, J., Svobodova, \& Z., Hajslova, J. (2008). Effects of pollution on chub in the River Elbe, Czech Republic. Ecotoxicology and Environmental Safety. doi:10.1016/j.ecoenv.2008.09.020.

Sanchez, W., Katsiadaki, I., Piccini, B., Ditche, J. M.,Porcher, J. M. 2008. Biomarker responses in wild three-spined stickle back (Gasterosteus aculeatus L.) as a useful tool for fresh water biomonitoring: a multiparametric approach. Environment International, 34(4), 490-498.

Sastry, K. V., \& Sunita, K. (1984). Chronic toxic effects of chromium in Channa punctatus. J. Environ. Biol., 5, 47-52.

Sindhe, V. R., \& Kulkarni, R. S. (2004). Gonadosomatic and hepatosomatic indices of the freshwater fish Notopterus notopterus (Pallas) in response to some heavy metal exposure. Journal of Environmental Biology/Academy of Environmental Biology, India, 25(3), 365-368.

Vives, I., Grimalt, J., Fernandez, P., \& Rosseland, B. (2004). Polycyclic aromatic hydrocarbons in fish from remote and high mountain lakes in Europaand Greenland. Science of the Total Environment, 324,67-77.

Yılmaz, S., Yılmaz, M., Polat, N., \& Bostanc1, D. (2007). Altınkaya Baraj Gölü (Samsun, Türkiye)'nde yaşayan sudak balığı Sander lucioperca (L., 1758)'nın yaş ve büyüme özellikleri. Fırat Üniversitesi Fen ve Mühendislik Bilimleri Dergisi, 19(3), 273-283. 